\title{
The Field Epidemiology \\ Training Program at the LCDC
}

J HOCKIN, MD, MSC

$\mathrm{T}$ HE FIELD EPIDEMIOLOGY TRAINING PROGRAM AT the Laboratory Centre for Disease Control (LCDC) was established in 1975 to provide Canadian physicians with an opportunity to acquire practical experience in the application of epidemiological principles during a two year public health apprenticeship. The program was a response to provincial requests for federal assistance in providing public health training in Canada. Since then, opportunities for community medicine training have rapidly expanded, and the LCDC has adapted to these changes in many ways. This LCDC report will describe the history and future directions of the Field Epidemiology Training Program. I will begin with a brief reminiscence.

In May 1991 the LCDC celebrated the career of Dr Gordon Jessamine on the occasion of his retirement from Health and Welfare Canada. Gordon is known to many for his work with tuberculosis as a surgeon, administrator, epidemiologist and policy maker, and for his tireless work in helping Canadians recognize, understand, treat and prevent sexually transmitted diseases. Gordon was my mentor and former Chief at the LCDC.

I was fortunate enough to spot an advertisement in the January 1981 issue of The Canadian Medical Association Journal which offered physicians a chance to work with provincial epidemiologists in various locations across the country. While considering a residency in either pathology or the relatively new specialty of community medicine, I saw the Field Epidemiology Training Program as a way to test my interest in public health, and an opportunity to return to Toronto from Ottawa. The next two years in Newfoundland were the most broadening and exciting of my career in public health! The program was not perfect and the budget woefully inadequate, but I caught a spark from Gordon, and from David
Severs of St John's, which continues to drive me. Do the other 37 graduates of this program share my sentiment? They certainly were not turned off by the experience. Eight are senior consultants in provincial ministries of health, including six provincial or territorial epidemiologists; three work at Health and Welfare Canada; another 11 are medical officers of health; and three hold full time academic appointments. Nine hold fellowships in community medicine.

From the beginning, the Field Epidemiology Training Program was modelled after the Centers for Disease Control (CDC) Epidemic Intelligence Service Program (1). The CDC format of providing a brief formal training course followed by a two year apprenticeship was an immediate success, with one to three physicians entering the program each year. Provincial assignments were, for the most part, in communicable disease control. However, field epidemiologists have also investigated sudden deaths, cancer clusters, natural disasters and new syndromes (Table 1). When field epidemiologists complained about not receiving formal credit for the training period (in the United States, institutions such as the CDC are accredited for postgraduate medical training), a liaison was established with the Departments of Community Medicine in Ottawa, Toronto, Winnipeg and Vancouver, to accept residents into the program.

Following the national outbreak of amnesic shellfish poisoning (encephalopathy caused by domoic acid) in 1987 (2), Health and Welfare Canada launched a food safety initiative aimed at earlier recognition, control and prevention of foodborne disease. One aspect of the initiative was to strengthen the LCDC's response to outbreaks through the Field Epidemiology Training Program. The budget was increased to support up to 10 salaried training positions. With five or more incoming officers each year, it has become feasible 


\section{TABLE 1 \\ Selected investigations involving Laboratory Centre for Disease Control field epidemiologists}

Medication errors mimicking neonatal sepsis (3) *

Sudden deaths in a pediatric cardiac unit (4)*

Salmonella typhimurium outbreak from cheddar cheese (5)

Surveillance of chemical weapons use against refugees

coming to Thailand (6)

Deaths and injuries following a tornado (7)

An outbreak of veritoxigenic Escherichia coli infection at a

nursing home (8)

Botulism associated with bottled garlic (9)*

Encephalopathy following ingestion of toxic mussels (2)

"Coinvestigation with Centers for Disease Control

to provide an intensive course in Ottawa at the start of training. The course has been open to University of Ottawa residents contemplating elective or core rotations at the LCDC, but is deliberately kept small enough to permit personal attention to the varying needs of incoming officers. Teaching modules include lectures, case studies and a field study. Field studies performed in the past two years were a survey of seatbelt use and a salmonella outbreak investigation.

Field epidemiologists are currently assigned to the British Columbia Centre for Disease Control, the Alberta Health Department's Communicable Disease Epidemiology Division, the Ontario Ministry of Health, the Nova Scotia Department of Fitness and Health, the Waterloo District Health Unit and the LCDC. LCDC assignments include base projects in enteric disease and childhood immunization.

The current trainees have come with a variety of qualifications, including two with Royal College certification in infectious diseases, a pediatrician, a microbiologist, two with Master's degrees and a veterinary epidemiologist. More trainees will allow greater flexibility in responding to requests from

\section{REFERENCES}

1. Thacker SB, Goodman RA, Dicker RC. Training and service in public health practice, 1951-90CDC's Epidemic Intelligence Service. Public Health Rep 1990;105:599-604.

2. Perl TM, Bédard L, Kosatsky T, Hockin JC, Todd ECD, Remis RS. An outbreak of toxic encephalopathy caused by eating mussels contaminated with domoic acid. N Engl J Med 1990;322:1775-80.

3. Solomon SL, Wallace EM, Ford-Jones EL, et al. Medication errors with inhalant epinephrine mimicking an epidemic of neonatal sepsis. N Engl J Med 1984;310:166-70.

4. Buehler JW, Smith LF, Wallace EM, Heath CW, Kusiak R, Herndon JL. Unexplained deaths in a children's hospital. An epidemiologic assessment. N Engl J Med 1985;313:211-6.

5. Laboratory Centre for Disease Control. provinces without a field epidemiologist and in assigning someone with appropriate expertise and interest to a given outbreak or surveillance project.

During an outbreak or field study, the field epidemiologist is supervised by the local medical officer or disease control epidemiologist, who remains responsible for the investigation. An LCDC supervisor from the Field Epidemiology Division provides consultation and general direction to the field epidemiologist. When appropriate, the first year field epidemiologist is accompanied by a more experienced staff member at the outset of an investigation. This dual supervision is consistent with the objective of the program to provide a training experience while supporting local disease control efforts. Written reports are provided to the requesting agency with copies to the province and to the LCDC. Whenever possible, a field epidemiologist is assigned to an outbreak on a full-time onsite basis during active investigation. Travel costs within an assigned province are assumed by the provincial department; all other travel costs are covered by the LCDC.

Field epidemiologists are available to assist any public health agency or institution in the investigation of any outbreak or other occurrence of disease. Requests for assistance are normally made through the appropriate responsible local or provincial agency. Direct requests to the LCDC are discussed with the provincial epidemiologist in all cases. Medical Officers of Health and physicians in institutions are encouraged to request the assistance of a field epidemiologist as soon as possible after an outbreak is recognized. This provides the requesting agency with additional help early in an investigation, makes LCDC collaboration more efficient, and gives the field epidemiologist a better experience. The LCDC $24 \mathrm{~h}$ emergency phone number is (613) 957-0323.

Food-preference survey to investigate

$S$ typhimurium cases - New Brunswick. Can Dis Weekly Rep 1984;10:133-4.

6. Hockin JC, Allison DJ. Investigations into the alleged use of chemical/biological weapons in SE Asia, 1983-84. Report to: Arms Control and Disarmament Division, Department of External Affairs, Ottawa, June 1984.

7. Carter AO, Millson ME, Allen DE. Epidemiologic study of deaths and injuries due to tornadoes. Am J Epidemiol 1989;130:1209-18.

8. Carter AO, Borczyk AA, Carlson JAK, et al. A severe outbreak of Escherichia coli 0157: H7- associated hemorrhagic colitis in a nursing home. N Engl J Med 1987;317:1496-500.

9. St Louis ME, Peck SH, Bowering D, et al. Botulism from chopped garlic: Delayed recognition of a major outbreak. Ann Intern Med 1988; 108:363-8. 


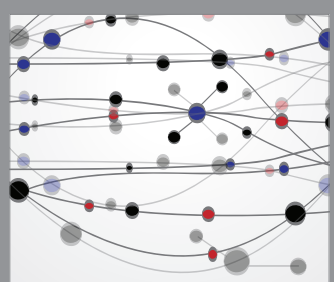

The Scientific World Journal
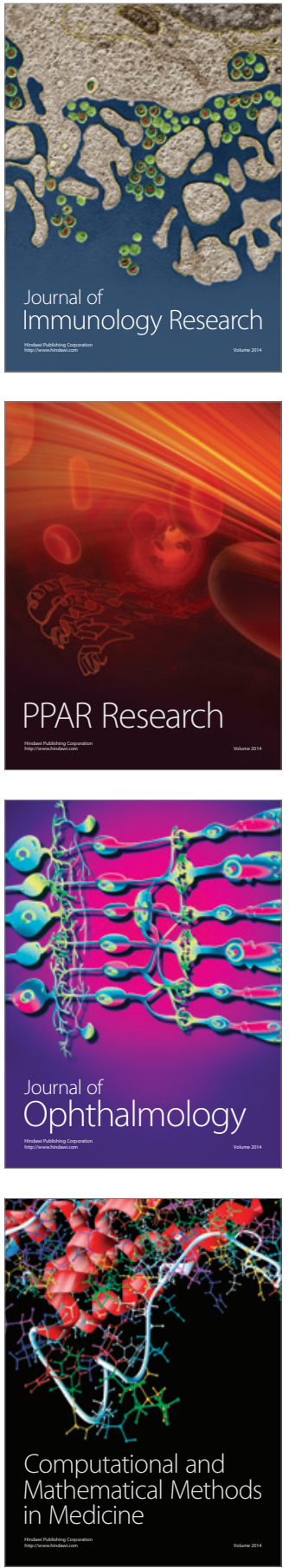

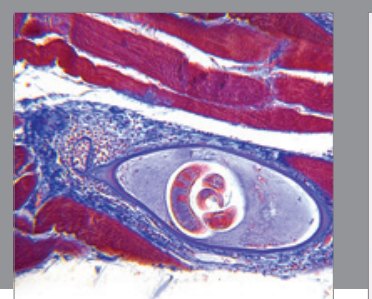

Gastroenterology Research and Practice

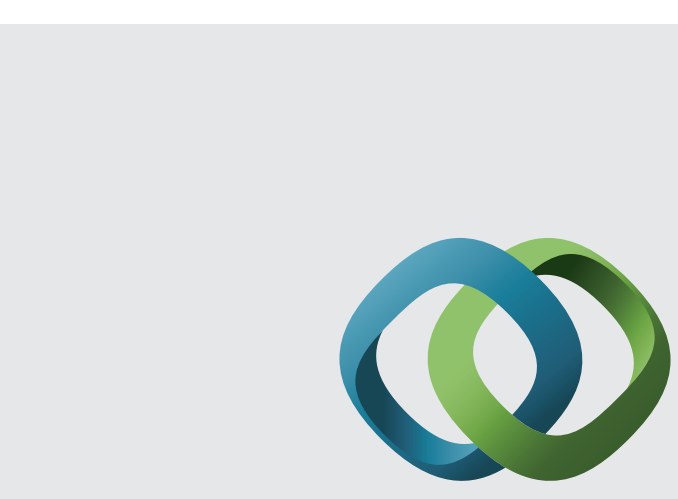

\section{Hindawi}

Submit your manuscripts at

http://www.hindawi.com
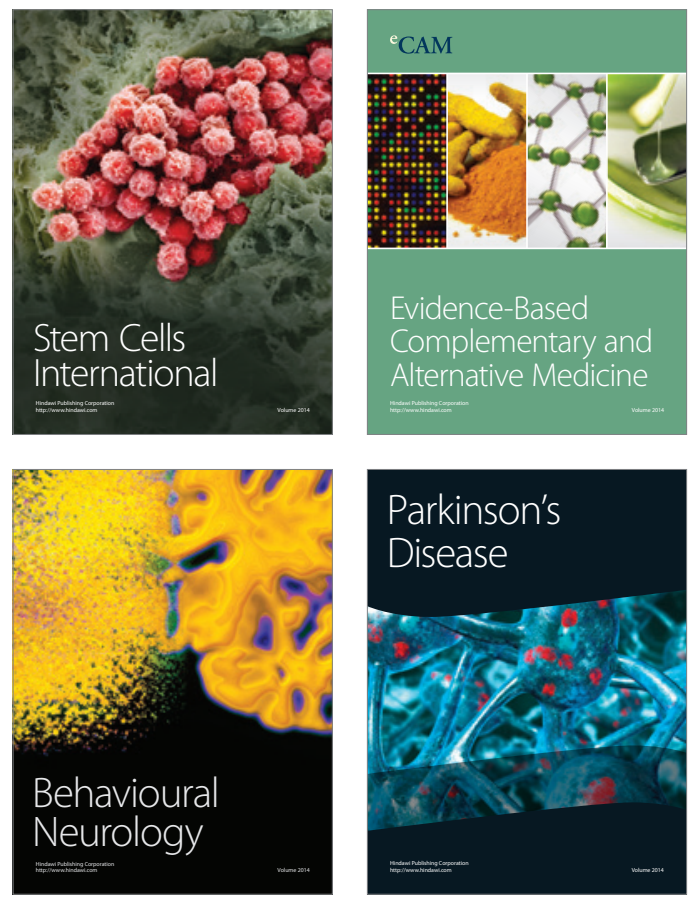
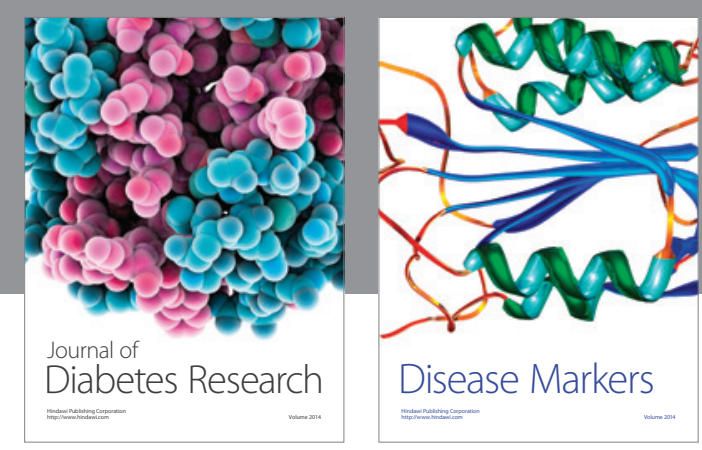

Disease Markers
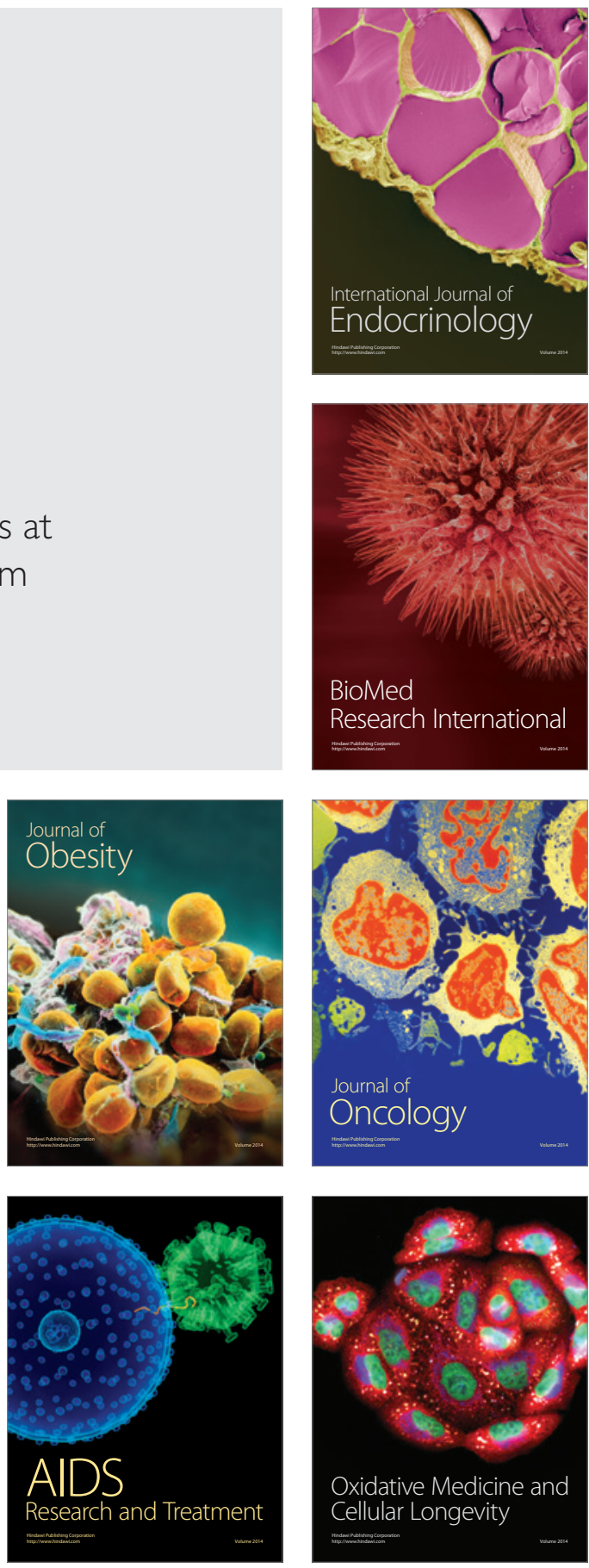